\title{
INTERPRETACIÓN Y GARANTÍA DE LOS DERECHOS FUNDAMENTALES POR EL DEFENSOR DEL PUEBLO (Análisis empírico, reconstrucción dogmática y propuesta del futuro)*
}

\author{
GUILLERMO ESCOBAR ROCA \\ Profesor Titular de Derecho Constitucional \\ Universidad de Alcalá
}

\author{
SUMARIO \\ I. Planteamiento. \\ II. Aproximación inicial al modelo de con- \\ trol desarrollado por el Defensor del \\ Pueblo. \\ III. Sistematización de las recomendaciones. \\ IV. El Defensor del Pueblo y las tendencias \\ actuales de la dogmática de los dere- \\ chos. \\ V. Valoración y propuesta.
}

\section{PLANTEAMIENTO}

Hace ya casi tres décadas que comenzó la actividad del Defensor del Pueblo (en adelante, DP), plasmada sobre todo en igual número de Informes ordinarios (con sus correspondientes recopilaciones de "recomendaciones y sugerencias") y en veinticuatro Informes llamados extraordinarios, sobre las más diversas materias ${ }^{1}$. Hasta la fecha, la doctrina española ha estudiado esencialmente sus aspectos organizativos y competenciales (el DP como órgano $^{2}$ )

* Agradecemos a Alejandra Celi y Carlos Trelles, investigadores del Programa Regional de Apoyo a las Defensorías del Pueblo de Iberoamérica, de la Universidad de Alcalá, sus útiles comentarios a una versión preliminar de este trabajo.

1 Todos los documentos están disponibles en http://www.defensordelpueblo.es.

2 La bibliografía es amplia, por lo que conviene una selección, remitiendo al efecto a la contenida en G. ESCOBAR ROCA (dir.), Defensorías del Pueblo en Iberoamérica, Thomson-Aranzadi, 
pero apenas el contenido material de sus actuaciones (la doctrina del DP³). Se trata de una laguna grave de nuestra dogmática constitucional, que convendría colmar, y ello, entre otras, por las razones siguientes:

1) Se contribuiría a mitigar la varias veces denunciada judicialización de nuestro Derecho constitucional ${ }^{4}$. Sin duda, la Constitución es algo más de lo que el Tribunal Constitucional dice que es. Más en concreto, reducir el estudio (y la enseñanza, preciso es destacarlo en estos tiempos de recortes de los programas docentes) de los derechos fundamentales a la exposición, aunque sea crítica, de la jurisprudencia constitucional (precedida, como es obvio, de la legislación de desarrollo), que es la perspectiva dominante en los manuales al uso, resulta empobrecedor y, sobre todo, deformante, más ahora, cuando tras la reciente reforma del artículo 50 LOTC, tres magistrados pueden decidir, de forma prácticamente discrecional y ajena a todo control $^{5}$, lo que resulta o no de "trascendencia constitucional". En contraste, la doctrina del DP ofrece una perspectiva de la Constitución más amplia, por la extensión de sus ámbitos de su actuación ${ }^{6}$, y menos legalista ${ }^{7}$, por las formas de su argumentación.

Cizur Menor, 2008, págs. 189-191. Entre la bibliografía posterior cabe destacar: G. CARBALLO MARTÍNEZ, La mediación administrativa y el Defensor del Pueblo, Thomson-Aranzadi, Cizur Menor, 2008; A. PÉREZ CALVO, "El Defensor del Pueblo", en El Defensor del Pueblo de Navarra, Gobierno de Navarra, Pamplona, 2009; G. ESCOBAR ROCA, "La protección de los derechos sociales por las Defensorías del Pueblo" y J. J. FERNÁNDEZ RODRÍGUEZ, "Los nuevos retos de las Defensorías del Pueblo: bases para una reflexión", ambos en Memoria del X Congreso Iberoamericano de Derecho Constitucional, PUCP, Lima, 2009; A. E. PÉREZ LUÑO, "Las funciones del Defensor del Pueblo en el Estado constitucional, en Nuevos retos del Estado constitucional: valores, derechos y garantías, Universidad de Alcalá, Alcalá de Henares, 2010; así como los trabajos de M. PÉREZ-UGENA y A. J. PORRAS incluidos en la obra colectiva disponible en Internet El Ararteko: un Ombudsman para el siglo XXI, Ararteko, Vitoria, 2009.

3 Existen algunos artículos, normalmente breves y descriptivos, sobre derechos concretos. El único intento de aproximación global, en todo caso no exhaustiva, que conocemos es M. J. CORCHETE MARTÍN, El Defensor del Pueblo y la protección de los derechos, Universidad de Salamanca, Salamanca, 2001, págs. 160-171. Una aproximación similar a la nuestra, no exhaustiva sino ejemplificativa, es la del citado trabajo de CARBALLO MARTíNEZ (págs. 389-498), una obra imprescindible para el estudio del DP, por mucho que discrepemos en algunos de sus planteamientos, como iremos comprobando.

4 Por todos, P. DE VEGA expresa esta preocupación con especial claridad: "la reducción de toda la problemática de la Constitución a una doctrina de la interpretación jurisprudencial, no pasa de ser una reducción injustificada y falaz" (El tránsito del positivismo jurídico al positivismo jurisprudencial en la doctrina constitucional", Teoría y Realidad Constitucional, n. ${ }^{\circ}$ 1, 1998, pág. 86).

5 Incluso doctrinal, pues las decisiones de inadmisión no se publican. La STC 155/2009 es un intento, nos tememos que insuficiente, de paliar este grave problema.

6 Como veremos después, en la doctrina del DP destaca el tratamiento de los derechos sociales (y de la faceta prestacional de los derechos de defensa) y de los derechos de los colectivos desfavorecidos, perspectivas ambas prácticamente inéditas en la jurisprudencia constitucional y por ende poco abordadas en nuestra dogmática.

7 Pese a los mencionados retazos críticos, más bien predomina entre nosotros un positivismo (constitucional) ideológico, en el sentido de N. BOBBIO (El positivismo jurídico, Debate, Madrid, 1993, págs. 227 y ss.), ¿̇ cuántas veces se lee en la doctrina que una norma (o una omisión) es 
2) Se comenzaría a construir un Derecho constitucional "desde abajo" el objetivo último de toda Constitución es lograr la integración política, es decir, la identificación de los ciudadanos con el Estado?, y si este objetivo es compartido, como creemos deseable, por la dogmática constitucional, parece evidente que esta ${ }^{10}$ no debe caminar al margen de los intereses y aspiraciones de los ciudadanos ${ }^{11}$. La Constitución no es sólo un marco de actuación de los poderes públicos sino también un instrumento para lograr el bienestar de cuantos integran la nación española, como dice su mismo Preámbulo, en este punto tantas veces olvidado. Salvo que se profese un paternalismo extremo, incompatible con el espíritu de la misma Constitución, no debería construirse una dogmática de los derechos de los ciudadanos sin tener en cuenta a (todos) los ciudadanos, y las aspiraciones de estos se reflejan mejor en la actividad del DP que en las demandas de los abogados y las decisiones de los jueces $^{12}$. El DP, que carece de los filtros legales, económicos y sociológicos propios de la jurisdicción ${ }^{13}$, es un buen mediador entre la sociedad y el Esta-

inconstitucional, sin que antes lo haya dicho el Tribunal Constitucional? De otro lado, que el Derecho constitucional es algo más que Derecho ya fue puesto de manifiesto de forma clara, entre otros, por P. LUCAS VERDÚ. Últimamente, p. ej., D. GRIMM, «Identidad y transformación: la Ley Fundamental en 1949 y hoy", Teoría y Realidad Constitucional, n. ${ }^{\circ}$ 25, 2010, pág. 274: "La Constitución es [...] no sólo un texto jurídico, sino también la "reserva de sentido" de la sociedad, expresión de la concepción que ésta tiene de sí misma y de sus aspiraciones supremas".

8 Tomamos prestada la expresión del libro editado por B. DE SOUSA SANTOS y C. A. RODRÍGUEZ GARAVITO, El derecho y la globalización desde abajo, Anthropos, Barcelona, 2007. Entre nosotros, G. PISARELLO adopta este planteamiento (Los derechos sociales y sus garantias, Trotta, Madrid, 2007, esp. págs., 136-138), pero pensando más en las garantías de los derechos que en la definición de los mismos.

9 Por todos, K. HESSE, Escritos de Derecho constitucional, CEC, Madrid, 1983, pág. 50, con evidente inspiración en SMEND.

10 Como tampoco la jurisprudencia, y en ese sentido entendemos la fórmula del art. 117.1 CE según la cual "La justicia emana del pueblo", expresión que evoca el sentido filosófico clásico del verbo "emanar", que significa, "fluir continuamente"; de interés, J. FERRATER MORA, "Emanación", en Diccionario de Filosofía, Círculo de Lectores, Barcelona, 1991, t. 2, págs. 911-912. La cita no es baladí, pues refleja bien la concepción de la democracia que justifica la creación del DP.

11 Mirando desde más lejos, el origen de las Defensorías del Pueblo en los países de escasa tradición democrática (como el nuestro y la mayoría de los latinoamericanos) guarda relación con la necesidad de reconciliar a los ciudadanos con el Estado, creando al efecto instituciones de rendición de cuentas; de interés, G. O’DONNELL, "Accountability horizontal: la institucionalización legal de la desconfianza política", Revista Española de Ciencia Política, n. ${ }^{\circ} 11,2004$, págs. 11 y ss. y M. SENEVIRANTNE, "Researching Ombudsmen", en R. Banakar y M. Travers (eds.), Theory and Method in socio-legal research, Hart, Portland, 2005, págs. 160 y ss., donde se defiende explícitamente la utilidad del estudio de las Defensorías del Pueblo para la Ciencia política y de la Administración.

12 Una de nuestras mayores sorpresas de nuestra experiencia de cinco años como magistrado de la Sala de lo Contencioso-Administrativo de la Audiencia Nacional fue el tipo de demandas que llegaban: raramente los grandes problemas de derechos fundamentales de nuestro país y con demasiada frecuencia asuntos de bagatela.

13 Conviene recordar que puede dirigirse al DP «toda persona natural o jurídica que invoque un interés legítimo" (art. 10.1 LODP), lo que incluye a las organizaciones no gubernamentales y a las asociaciones para la defensa de intereses colectivos, que acuden con frecuencia a la institución. Además, en la práctica se hace un uso flexible del requisito del interés y, de cualquier 
do, un instrumento de participación ciudadana ${ }^{14}$, y el análisis de su doctrina es una buena forma de conocer las inquietudes actuales, reales y concretas, de la sociedad española ${ }^{15}$.

3) Se conectaría la realidad social de los derechos (lo que los ciudadanos dicen que son sus derechos) con las más modernas tendencias dogmáticas, en un juego de alimentación recíproca: se sorprenderá el lector al comprobar cómo las más relevantes propuestas de renovación dogmática de los derechos, sólo tardía y fragmentariamente aceptadas por la jurisprudencia ${ }^{16}$, encuentran su paralelo en la doctrina (normalmente implícita) del DP. Conociendo esta doctrina, la dogmática podría aprender a salir de sí misma, a construirse (la ciencia progresa día a día) de forma más democrática y socialmente útil, teniendo a la vista las aspiraciones de los ciudadanos (si la dogmática no sirviera para solucionar los problemas reales de las personas reales, renunciaría a su principal cometido), y para conocer cuáles son éstas el DP puede ofrecer una imagen bastante fiel.

Este trabajo no va a exponer la rica y profusa doctrina del DP, elaborada durante cerca de tres décadas, tarea esta sin duda necesaria pero casi hercúlea, merecedora más de una monografía o de una tesis doctoral que de un artículo dirigido a una revista científica, con sus obvias limitaciones de espacio. Nuestro objetivo es más modesto: sobre la base de las recomendaciones del último Informe publicado, el correspondiente a 2008 (un material que creemos suficientemente significativo: 121 recomendaciones), analizaremos el

modo, el DP puede actuar de oficio, en cuyo caso no se exigiría la presencia de dicho interés. Como se advierte, la legitimación es amplísima, y por si quedaran dudas, el propio artículo 10.1 señala que "no podrán constituir impedimento [para el acceso al DP] la nacionalidad, residencia, sexo, minoría de edad, la incapacidad legal del sujeto, el internamiento en un centro penitenciario o de reclusión o, en general, cualquier relación especial de sujeción o dependencia de una Administración o Poder Público". Como se advierte, se va mucho más allá de la legitimación exigida en el Derecho español para iniciar un procedimiento administrativo (art. 31 LPC) o judicial (art. 19 LJCA). Además, el procedimiento es gratuito (art. 15.2 LODP).

14 Para profundizar en esta línea sigue siendo útil el trabajo de J. L. CASCAJO CASTRO, “Los Defensores del Pueblo en el Estado social y democrático de Derecho: una perspectiva teórica", Revista Vasca de Administración Pública, n. ${ }^{\circ} 24,1989$, págs. 43 y ss.

15 Así, R. RAMOS TORRE y J. V. GÓMEZ RIVAS, El Defensor del Pueblo en una España en cambio, Trama, Madrid, 2007, págs. 112 y ss.

16 La dogmática ha de ir por delante, no por detrás de la jurisprudencia. No resistimos la cita de este fragmento de uno de los más importantes constitucionalistas vivos: "El actual derecho constitucional [nuestro autor se refiere a la dogmática constitucional] ha renunciado visiblemente a sus principales tareas. En vez de intentar síntesis histórico-culturales de la época constitucional presente, como base de elaboraciones abiertas al porvenir, su máxima aspiración es proponerse como prontuario de soluciones inevitablemente dirigidas al pasado. Así, el derecho constitucional termina por configurarse como una continua búsqueda de medios de emergencia, perennemente retardataria y necesariamente instrumentalizada e instrumentalizada en sentido político. De este modo, el derecho constitucional se contenta continuamente con ser un subproducto de la historia y de la política, en vez de intentar convertirse al menos en una fuerza autónomamente constitutiva tanto de una como de otra" (G. ZAGREBELSKY, Historia y Constitución, Trotta, Madrid, 2005, págs. 27-28). 
modelo de protección de los derechos realizado por el DP, las formas de razonar utilizadas en sus recomendaciones y la conexión de los leitmotiv de su implícita doctrina con algunas de las tendencias más significativas de la dogmática actual de los derechos, concluyendo con una valoración crítica y prospectiva. Nuestro estudio será de dogmática jurídica, mezclando por tanto las tareas descriptiva, conceptualizadora, sistematizadora, interpretativa y crítica de las normas y de su aplicación, pero acentuando de modo especial la segunda y la tercera de tales tareas.

\section{APROXIMACIÓN INICIAL AL MODELO DE CONTROL DESARROLLADO POR EL DEFENSOR DEL PUEBLO}

Como pórtico a este trabajo, conviene recordar brevemente la especificidad del modo de protección de los derechos (después aclararemos de qué derechos se trata) desarrollado por el DP, atendiendo al efecto no sólo a su regulación legal (Ley Orgánica 3/1982, del Defensor del Pueblo, en adelante, LODP), en la que suelen quedarse los estudiosos de la materia, sino también y sobre todo a su práctica real. El modo de protección es peculiar (también para el ámbito habitual de nuestro Derecho constitucional comparado ${ }^{17}$ ), de ahí que pueda hablarse, como hacemos en el título de este epígrafe, de la existencia de un modelo. De entrada, debe señalarse que las competencias más características de la Institución encajan en el concepto amplio de control, defendido entre nosotros por la doctrina más solvente ${ }^{18}$ : existen un sujeto y un objeto de control, un parámetro de control y unos efectos del control. Veámoslo brevemente:

\section{Sujetos}

El sujeto controlado por el DP es ante todo la Administración. El artículo 54 CE alude exclusiva y genéricamente a ella, sin más precisiones. El artículo 9 LODP aporta dos amplias definiciones de Administración: «la Administración pública y sus agentes" y "los ministros, autoridades administrativas, funcionarios y cualquier persona que actúe al servicio de las Administraciones públicas". El artículo 12, por su parte, añade, genéricamente, "la Comunidad Autónoma». En la práctica, el DP ejerce control sobre: a) el Gobierno de la nación y la Administración General del Estado, en su más amplio sentido, pu-

17 No existe un modelo similar en los países que acostumbramos a estudiar (Italia, Alemania y Francia, aunque en este último está a punto de entrar en vigor una nueva legislación, muy próxima a la nuestra), de ahí la ausencia en este trabajo de bibliografía específica sobre el Defensor del Pueblo en lenguas foráneas.

18 M. ARAGÓN, Constitución y control del poder, Ediciones Ciudad Argentina, Buenos Aires, 1995, págs. 67 y ss. 
diendo acudirse, para su concreción, a la LOFAGE ${ }^{19}$. La práctica demuestra que el Defensor ejerce control sobre la Administración exterior y sobre las empresas públicas ${ }^{20}$; b) los Gobiernos autonómicos y sus respectivas Administraciones ${ }^{21}$, si bien en la práctica el DP cede este control a las instituciones homólogas en los casos de doble solicitud; c) la Administración local: si bien la LODP nada dice sobre ello, según la Ley 36/1985, coherente en esto con los primeros Estatutos de Autonomía, «la supervisión [...] de las Administraciones de los entes locales, cuando actúen en ejercicio de competencias delegadas por [la Comunidad Autónoma] se podrá realizar [...] por el Defensor del Pueblo y el comisionado parlamentario autonómico en régimen de cooperación, [...] en todo aquello que afecta a materias sobre las cuales se atribuyan competencias a la Comunidad Autónoma en la Constitución y en el respectivo Estatuto de Autonomía y sin mengua de [las] facultades del Defensor del Pueblo" (art. 2.1). En la práctica, el control de la Administración local se comparte entre el DP y sus homólogos autonómicos, sin atenderse al requisito de la delegación de competencias autonómicas; d) aunque nada dice la ley, el DP ha extendido su control a la Administración electoral y al Consejo General del Poder Judicial ${ }^{22}$.

La principal duda que plantea la legislación vigente es si el DP tiene competencia para controlar a las empresas concesionarias de servicios públicos y a las que prestan servicios de interés general ${ }^{23}$ : ambos tipos de empresas no son Administración pero afectan a materias importantes para los ciudadanos que, por su naturaleza, resultan próximas al ámbito natural de actuación del DP. Sólo las primeras, y desde una generosa interpretación del término "al servicio de las Administraciones públicas" (a lo que se suma la referencia, en el art. 19.2, a los centros afectos a un servicio público y en el art. 28.3, a los "ser-

$19 \mathrm{El}$ art. 14 LODP hace una especial referencia a la Administración militar, únicamente para señalar que se encuentra también sujeta al control del DP pero "sin que ello pueda entrañar una interferencia en el mando de la Defensa Nacional.

20 El control de las empresas públicas es poco frecuente, pero legalmente cabe, y así lo señala E. MÚGICA HERZOG, en su intervención en el debate "Situación y perspectivas de las Defensorías del Pueblo de Iberoamérica", Cuadernos Electrónicos de Democracia y Derechos Humanos, n. ${ }^{\circ}$ 3, 2007, pág. 130.

21 Vid., recientemente, el FJ 33 de la STC 31/2010, declarando inconstitucional la pretensión del Estatuto de Cataluña de excluir el control de la Administración catalana por parte del DP.

22 Lo que entendemos legítimo, pues el DP no está sujeto al principio de vinculación positiva propio de la Administración. Téngase en cuenta además que sus resoluciones carecen de efectos coactivos, por lo que el principio de legalidad debe flexibilizarse en relación con la institución que estudiamos. Para una panorámica del debate, creemos que ya cerrado, G. CARBALLO MARTÍNEZ, La Mediación..., cit., págs. 252-253.

23 El Estatuto de Cataluña, no declarado aquí inconstitucional, incorpora esta preocupación, atribuyendo expresamente al Sindic de Greuges la supervisión de "las empresas privadas que gestionan servicios públicos o realizan actividades de interés general o universal o actividades equivalentes de forma concertada o indirecta y la de las demás personas con vínculo contractual con la Administración [...] y con las entidades públicas dependientes de ella". Esta tendencia se va imponiendo en el Derecho constitucional comparado; vid., p. ej., las recientes Constituciones de Bolivia (art. 218), Ecuador (art. 215) y República Dominicana (arts. 192 y 281.2). 
vicios prestados por particulares en virtud de acto administrativo habilitante"), encuentra cobijo en la legislación vigente. Sin embargo, la actuación del DP se ha extendido en la práctica, en algunas ocasiones, a unas y otras, pues "el ámbito de competencias debe adaptarse a los cambios en la sociedad, no pudiendo permanecer limitado a la Administración pública tradicional ${ }^{24}$.

Aunque nada dice expresamente el artículo $54 \mathrm{CE}$, el DP puede controlar, en cierta medida, al Parlamento del que es comisionado, pues el artículo 28.2 LODP permite a aquél realizar sugerencias a este. Además, puede presentar recurso de inconstitucionalidad contra las leyes (arts. 162.1 a) CE y 29 LODP).

En cuanto al Poder Judicial, según el artículo 13 LODP, las "quejas referidas al funcionamiento de la Administración de Justicia" deben ser dirigidas al Ministerio Fiscal o al Consejo General del Poder Judicial, "sin perjuicio de la referencia que en su informe general a las Cortes Generales pueda hacer al tema». En la práctica, esta previsión, unida al hecho de que el Poder Judicial no aparece expresamente en la Ley como objeto de control, se interpreta en el sentido de que el DP controla, tanto en las quejas como en los informes, los aspectos administrativos de la Justicia ${ }^{25}$, no la actividad jurisdiccional propiamente dicha.

Por último, en cuanto a los particulares, salvo los supuestos citados de empresas concesionarias de servicios públicos o prestadoras de servicios de interés general, el DP carece de competencias expresas. Sin embargo, como después veremos, controla indirectamente a los particulares, al controlar a la Administración que debió proteger los derechos fundamentales frente a las vulneraciones privadas a los mismos ${ }^{26}$.

\section{2. Овјето}

El artículo 9.1 LODP habla de "actos y resoluciones", a lo que los artículos 23 y 28.1 añaden, respectivamente, las omisiones y las normas. En la práctica, encontrándose dentro del ámbito subjetivo de control, el DP ejerce un control total, que incluye normas (normas con rango de $\operatorname{ley}^{27} \mathrm{y}$ reglamentos), actos

24 E. MÚGICA HERZOG, cit., pág. 130. P. ej., en el Informe de 2009 (pág. 943 y ss.) encontramos actuaciones contra Telefónica SA, empresa netamente privada, que presta "servicios de interés general" y está sujeta a algunas "obligaciones de servicio público" (respectivamente, art. 2.1 y Título III de la Ley 32/2003).

25 Vid., p. ej, en el Informe de 2009, la relación de temas tratados bajo el rótulo "Administración de Justician: dilaciones indebidas, servicio público judicial, atención a menores o registro civil, entre otras.

26 E. MÚGICA HERZOG, cit., pág. 130. P. ej., en el Informe de 2009 pueden citarse los casos de supervisión administrativa de la actividad económica de empresas privadas, de actividades dañosas para el medio ambiente o de medios de comunicación (en cuanto a su obligación de controlar los abusos privados contra los derechos de la juventud e infancia).

27 No resulta aplicable al DP el llamado privilegio jurisdiccional de la ley, que obliga a los jueces y tribunales, cuando consideren que una ley es inconstitucional, a plantear la cuestión ante el Tribunal Constitucional (art. 163 CE). La explicación se encuentra en que, como veremos seguidamente, el parámetro de control no es para el DP estrictamente jurídico. 
(incluyendo los sujetos al Derecho privado), vía de hecho y omisiones ${ }^{28}$ de los sujetos controlados.

Los actos discrecionales de la Administración no están exentos de control $^{29}$, si bien este puede lógicamente atemperarse para aquellos, atendiendo a las circunstancias de cada caso concreto.

\section{PARÁmetro}

Según el artículo 54 CE, el parámetro de control realizado por el DP son los derechos del título I de la CE. Este parámetro se ha entendido generosamente (en la práctica, se protegen no sólo los derechos sino todo el título I ${ }^{30}$ ) y el artículo 9.1 LODP parece extenderlo (y así se ha interpretado) a los principios de la Administración pública del artículo 103.1 CE (servicio con objetividad los intereses generales, eficacia, jerarquía, descentralización, desconcentración, coordinación y sometimiento pleno a la ley y al Derecho), situados en la propia Ley en pie de igualdad con los derechos del título I.

Por su parte, los artículos 23 y 28.2 parecen ampliar aún más el parámetro, al aludir, sin referencia expresa a los derechos fundamentales, respectivamente, al "abuso, arbitrariedad, error, negligencia u omisión" y a las "situaciones injustas o perjudiciales para los administrados". Estos preceptos han conducido a una práctica institucional más cercana al control de la "mala administración" (en el sentido amplio de la expresión) que a la tutela de los derechos fundamentales. De hecho, los últimos informes no se estructuran por derechos sino por áreas de actuación administrativa. No hay impedimento jurídico a esta forma de actuar, seguramente razonable, pero se echa en falta una mayor atención en los informes a la perspectiva propia de los derechos fundamentales (que, obviamente, son tratados de forma dispersa en buena parte del contenido de los informes), que además de emparentar mejor la Institución con el cometido constitucionalmente diseñado para la misma dotaría de mayor fuerza (autoridad moral, pues de eso se trata) a las recomendaciones.

Interesa detenerse brevemente en un punto que juzgamos esencial, la naturaleza de los derechos fundamentales como parámetro de control. Creemos que tales derechos deben ser entendidos de forma amplia, y así está sucediendo en la práctica. El DP (que en principio no puede tutelar derechos dis-

28 A la referencia a las omisiones del art. 23 puede añadirse la previsión de la última frase del art. 17.2, según la cual el DP «velará porque la Administración resuelva expresamente, en tiempo y forma, las peticiones y recursos que le hayan sido formulados".

29 Tampoco los actos políticos del Parlamento (interna corporis acta) ni los llamados actos políticos del Gobierno, en caso de que se admitiera esta categoría.

30 Sin ánimo de entrar en la polémica sobre si existen o no derechos fundamentales en el capítulo III del título I, parece claro que a lo largo de dicho título, y especialmente de dicho capítulo, existen mandatos a los poderes públicos que en apariencia (sólo en apariencia, como iremos viendo) no pueden subjetivizarse. 
tintos a los fundamentales) puede realizar determinaciones de su contenido que vayan más allá de las propuestas por el legislador e incluso por el Tribunal Constitucional. Es decir, puede exigir contenidos no previstos, acudiendo para ello a las cláusulas de apertura del catálogo español de derechos fundamentales: el principio de dignidad de la persona y el Derecho internacional. Creemos que la naturaleza de la Institución, tal y como aparece diseñada en su Ley reguladora (recuérdense sobre todo los ya citados arts. 23 y 28.2), bien permite un entendimiento del parámetro de control en términos no sólo de estricto Derecho positivo sino también de justicia, de derechos humanos $^{31}$. Desde esta perspectiva, y teniendo en cuenta que la justicia no es algo ajeno al Derecho positivo (art. 1.1 CE), podemos adelantar ya una de las tesis centrales de este trabajo (que explica no pocas de las coincidencias descritas en el posterior apartado IV): la concepción del Derecho que enmarca la actuación del DP es la propia del positivismo inclusivo o, más genéricamente, del llamado neoconstitucionalismo ${ }^{32}$, es decir, la adopción del Derecho positivo como parámetro de control pero también de los principios materiales de justicia, en la medida en que forman parte del mismo Derecho positivo ${ }^{33}$.

\section{EFECTOS}

Para sintetizar los efectos del control realizado por el DP, nos centraremos en el contenido de las resoluciones que ponen fin a los procedimientos de queja (iniciados por los sujetos legitimados para ello o de oficio). La LODP no es clara en la regulación de las formas de terminación de estos procedimientos. Cualquier resolución de cierre debe ser notificada al interesado (por extensión, art. 31.1) y a la Administración (arts. 23 y 31.3). De la normativa parece deducirse que el procedimiento puede terminar cuando el DP, tras realizar su propia investigación y analizar los informes que recibe de la Administración, considere que el interesado carece de fundamento en sus pretensiones, dando por buena la actuación de la Administración.

31 Como concepto diferente pero relacionado con el de derechos fundamentales, como quisimos destacar en G. ESCOBAR ROCA, Introducción a la teoría jurídica de los derechos humanos, Trama, Madrid, 2006, esp. págs. 35-38.

32 Por todos, respectivamente, J. J. MORESO y J. M. VILAJOSANA, Introducción a la teoría del Derecho, Marcial Pons, Madrid, 2004, págs. 199-200 y L. PRIETO SANCHÍS, "El constitucionalismo de los derechos", en M. Carbonell (ed.), Teoría del neoconstitucionalismo. Ensayos escogidos, Trotta, Madrid, 2007, págs. 213 y ss.

33 En su comentario al art. 23 LODP, J. M. DE PALACIO VALLE-LERSUNDI reconoce el carácter jurídico del parámetro de control, pero entroncándolo, a nuestro juicio de forma reduccionista, con las normas del procedimiento administrativo (en A. Rovira Viñas (dir.), Comentarios a la Ley Orgánica del Defensor del Pueblo, Thomson-Aranzadi, Cizur Menor, 2002, pág. 590). Tampoco nos convence del todo la posición de G. CARBALLO MARTÍNEZ (en La Mediación..., cit., pág. 356), cuando, también de forma reduccionista, vincula el parámetro con la buena administración y con la equidad, principio este último menos "jurídico" (a la vista del Derecho positivo español vigente) que la justicia y los derechos humanos. 
Algo más de claridad aporta la Ley al regular la terminación del procedimiento a favor del interesado. Si el resultado del control realizado es negativo para la Administración, los artículos 23, 28.2 y, sobre todo, 30.1, permiten cuatro tipos de resoluciones, que la práctica de la Institución ha reconducido a tres (las advertencias son escasísimas). La Ley no señala las diferencias entre ellas, por lo que se hace preciso acudir a los informes anuales para comprender cómo los términos legales son entendidos en la práctica ${ }^{34}$ :

a) Recomendación. El DP propone a la Administración el cambio de una actuación general, lo que, como veremos, suele implicar una de estas cinco cosas: aplicación de normas, cambio en la interpretación de normas, realización de un acto material, modificación de normas o creación de normas. Las recomendaciones son el núcleo de la actuación del DP y a analizar su tipología dedicaremos el epígrafe siguiente de este trabajo.

b) Sugerencia. El DP propone una actuación concreta, relativa a un ciudadano particular, lo que suele implicar bien un acto administrativo bien actuaciones materiales, con su correspondiente despliegue de medios personales o financieros. Así, tomando como ejemplo el Informe de 2006, para el primer caso, que se estime un recurso de alzada, se suministre información a un interesado o se paralice una expulsión del territorio nacional y, para el segundo, que se dote de colchonetas ignífugas a una comisaría local, se practique la medición sonométrica impuesta por la normativa contra la contaminación acústica o se realice una determinada prueba médica.

c) Recordatorio de deberes legales. En este tipo de resolución, similar a la recomendación, pues tiene, como esta, un alcance general, el DP pone el acento en la exigencia legal de realizar actuaciones administrativas, por lo que su ámbito natural es la lucha contra la inactividad del poder público. El recordatorio que aparece con mayor frecuencia es el de resolver de forma expresa las solicitudes de los ciudadanos.

Interesa destacar que, en cierto modo, en los tres tipos de resoluciones que ponen fin al procedimiento se busca (y muchas veces se consigue) lograr un efecto relativamente general (dependiendo del ámbito territorial de la Administración concernida), esto es, un beneficio para un amplio número de personas, lo que constituye una de las singularidades más interesantes del modelo de control ejercido por la Institución ${ }^{35}$. Lógicamente, esto se produce

34 Téngase en cuenta que la diferenciación entre el contenido de los distintos tipos de resoluciones no es tajante. A nuestro juicio, algunos contenidos podrían haber encontrado mejor acomodo en otro tipo de resolución. En todo caso, la cuestión no resulta de especial trascendencia práctica, pues los efectos de todas las resoluciones son los mismos. Para más detalles, G. CARBALLO MARTÍNEZ, La Mediación..., cit., págs. 310 y ss.

35 En las recomendaciones es frecuente leer la fórmula: "para que estas situaciones no vuelvan a repetirse" o "en el futuro" (p. ej., Recomendaciones 33/2008, 34/2008, 37/2008 o $38 / 2008$, entre muchas otras) aunque no pueda darse ya solución al problema concreto planteado por el interesado. En estos supuestos, los tribunales mirarían para otro lado (so pena de co- 
con mayor naturalidad en relación con las quejas colectivas, los procedimientos iniciados de oficio y las resoluciones que en sí mismas buscan dicho efecto general (recomendaciones y recordatorios de deberes legales).

En relación con los tres supuestos mencionados las sanciones posibles, normalmente compatibles entre sí, son las siguientes:

a) Nuevo recordatorio (una especie de ejecución de la resolución estimatoria) a la autoridad o funcionario para que responda sobre el cumplimiento de la resolución, por escrito y antes de un mes (art. 30.1 LODP) y, en su caso, información sobre el incumplimiento de la autoridad o funcionario al Ministro o máxima autoridad del Departamento concernido (art. 30.2).

b) Publicidad del incumplimiento. El señalamiento en el informe anual al funcionario, autoridad u órgano incumplidor, posible ya a lo largo del procedimiento, cobra ahora más sentido. Según el artículo 30.2 LODP, si tras el recordatorio y, en su caso, información antes referida, el DP "tampoco obtuviera una justificación adecuada, incluirá tal asunto en su informe anual o especial con mención de los nombres de las autoridades o funcionarios que hayan adoptado tal actitud, entre los casos en que, considerando el Defensor del Pueblo que era posible una solución positiva, esta no se ha conseguido".

c) Información al Fiscal General del Estado para que este ponga en marcha la acción penal, cuando el DP considere que se cometió un delito (art. 25.1).

d) Ejercicio de la acción de responsabilidad. El artículo 26 abre esta posibilidad pero no aclara a qué tipo de responsabilidad se refiere. A nuestro juicio, el precepto (hasta ahora nunca utilizado), al utilizar un término de ámbito judicial ("acción") y al eliminar el requisito de la previa reclamación por escrito (que recuerda al art. 142 LPC) parece aludir a la responsabilidad patrimonial.

Los datos proporcionados por la propia DP revelan el notable éxito de la misma $^{36}$. En un libro reciente, patrocinado por la Institución, se señala genéricamente que "en más de un tercio de los casos tramitados, las administraciones reconocen que sus actuaciones fueron irregulares y proceden a subsanarlas, dando de este modo razón o satisfacción, total o parcial, al titular o titulares de la queja, ${ }^{37}$. Más optimistas son todavía los datos del Informe

meter exceso de jurisdicción) o en el mejor de los casos impondrían una indemnización económica al afectado, sin resolver el problema de fondo.

36 A. NIETO, sagaz en tantos otros temas, no estuvo esta vez muy acertado al afirmar que "la función del Defensor del Pueblo no va mucho más allá de la de servir de buzón para la correspondencia que a unos fantásticos Reyes Magos de la política dirigen unos ciudadanos ilusos" (Mecanismos jurídicos de control del poder", en J. R. Capella (ed.), Las sombras del sistema constitucional español, Trotta, Madrid, 2003, pág. 392). A este eminente jurista le sugeriríamos apuntalar mejor las premisas fácticas de su razonamiento acudiendo a los datos empíricos. La tendencia resulta, por otra parte, general: M. SENEVIRANTNE, "Researching Ombudsmen", cit., págs. 172-173 o G. ESCOBAR ROCA, "Introducción”, en Defensorías del Pueblo..., cit., págs. 21 y ss.

37 R. RAMOS TORRE y J. V. GÓMEZ RIVAS, El Defensor del Pueblo..., cit., págs. 52-53. 
anual de 2009, que señalan un porcentaje de aceptación de recomendaciones del $75,6 \%$ para las emitidas en 2007 , con fecha de cierre de 31 de diciembre de 2009 .

\section{SISTEMATIZACIÓN DE LAS RECOMENDACIONES}

Como señalábamos en un comienzo, el análisis empírico de este trabajo va a centrarse en las recomendaciones incluidas en el último documento publicado por la Institución, referente a 2008. La lectura de las 121 recomendaciones emitidas en ese año pone nuevamente de manifiesto la anunciada determinación amplia del parámetro de control realizado por el DP: aproximadamente sólo la mitad de ellas guardan relación directa (aunque muchas veces no se dice de forma expresa; volveremos sobre este punto en el último epígrafe) con derechos fundamentales, pudiendo encuadrarse el resto en el concepto de "buena administración". Sin perjuicio de tratar más adelante sobre esto último, podemos sistematizar, como anunciábamos, las recomendaciones que sirven directamente a la protección de los derechos en cinco categorías principales ${ }^{38}$. Ejemplificaremos cada categoría en tres recomendaciones significativas ${ }^{39}$. Según las vayamos exponiendo, realizaremos tangenciales valoraciones provisionales (no tanto sobre el fondo del asunto como sobre el modo de argumentación) y adelantaremos algunas de las ideas que desarrollamos en los dos epígrafes finales de este trabajo. Nuestra selección y descripción de los ejemplos no será por tanto aséptica y muda sino dogmática y orientada.

38 Hemos manejado, como era obligado, la sistematización propuesta por G. CARBALLO MARTíNEZ, La Mediación...., cit., págs. 381-388 , pero no la seguiremos aquí, por resultarnos menos clarificadora y por encontrarse excesivamente lastrada por el leitmotiv de su obra (la equidad), en parte ya criticado en la nota 33.

39 La selección de ejemplos se realizará teniendo en cuenta, además de la adecuación a cada categoría, otros dos criterios: la relativa simplicidad del asunto (no conviene alargar estas páginas con la exposición de casos complejos) y la no repetición de derechos analizados, para mostrar mejor la amplitud (y heterogeneidad) del trabajo realizado por el DP. Hemos seleccionado casos sobre catorce derechos (lo son en la práctica de la institución) distintos: por orden de aparición en la CE, asilo, igualdad, libertad personal, intimidad, libertad de circulación, información veraz, acceso a la función pública, salud, medio ambiente, vivienda, protección de menores, protección de la tercera edad, protección de las personas con discapacidad y protección de los consumidores. Como derechos no incluidos en el catálogo de la CE, seleccionamos un caso sobre reagrupación familiar, implícitamente considerado derecho fundamental por el DP (con cita, por cierto, del Tribunal Europeo de Derechos Humanos y no del Tribunal Constitucional). 


\section{Aplicación de una norma que aparentemente no plantea problemas INTERPRETATIVOS}

Un limitado (estadísticamente hablando) número de recomendaciones ${ }^{40}$ se circunscribe a recordar al sujeto controlado que se aplique una norma, sin que aparentemente se planteen especiales problemas sobre la interpretación de la misma. Nos encontramos así ante un problema de eficacia del Derecho: existe una norma válida, útil para la protección de los derechos, pero que no se cumple. El DP actúa en estos casos al modo de las Regulatory Agencies, definidas como "órganos diseñados para el control y eficacia de las normas en materias de interés social y para informar y recibir propuestas", y ello, entre otras cosas, mediante el asesoramiento a la Administración, la información sobre la situación, obstáculos y remedios en torno a la eficacia de las normas, la advertencia y prevención sobre posibles incumplimientos y, en su caso, la sanción (en el sentido amplio del término) a los infractores ${ }^{41}$.

Como decíamos, este tipo de supuestos son poco habituales, pues normalmente la aplicación de una norma va acompañada de su previa interpretación ${ }^{42}$ y si la Administración no cumplió la norma es porque interpretó que no procedía su aplicación. Además, como después veremos, una buena parte de las recomendaciones del DP instando a la Administración a actuar (que son la mayoría) no apoyan su argumentación en normas claras y contundentes, esto es, no fundan directamente su razonamiento en el incumplimiento de una norma.

Veamos algunos ejemplos de este primer tipo de supuestos:

40 Téngase en cuenta que en estos casos cuadra mejor la fórmula del recordatorio de deberes legales. Sin embargo, con frecuencia en las recomendaciones se incluyen también, en la práctica y materialmente, este tipo de recordatorios.

41 La definición corresponde a R. SORIANO, Sociología del Derecho, Ariel, Barcelona, 1997, pág. 410. La crítica general de SORIANO a la eficacia real de estas agencias, paradójicamente creadas para paliar los problemas de eficacia de las normas, resultan aplicables a nuestro país: la Ley 28/2006, de Agencias Estatales para la Mejora de los Servicios Públicos, nació ya coja, pues si se mira bien, su objetivo no es exactamente el propio de las típicas Regulatory Agencies, al menos en los términos descritos por SORIANO. Por cierto, llama la atención que este autor no incluya en su análisis de los instrumentos de control de la ineficacia de las normas al DP, institución esta que podría resultar clave en este ámbito, si la Administración tomara más en serio los documentos emitidos por ella. En este orden de consideraciones, resulta significativo que nunca se haya dado cumplimiento a la moción aprobada por el Pleno del Congreso de los Diputados el 2 de octubre de 1995, en la que se instaba al Gobierno a promover reformas legislativas para que en el futuro el propio Gobierno diera "contestación escrita en documento único" al informe anual del DP, "a efectos de servir de referencia para el seguimiento por los Grupos Parlamentarios de cuál es la posición política del Gobierno respecto de las sugerencias, recomendaciones y recordatorios formulados por el Defensor del Pueblo en ese Informe anual y de las valoraciones que de aquéllas se desprenden".

42 El principio in claris non fit interpretatio resulta de aplicación excepcional. Es decir, casi siempre para aplicar una norma hay que interpretarla antes. Por todos, sirva el clásico: H. KELSEN, Teoría pura del Derecho, UNAM, México, 10. ${ }^{a}$ ed., 1998, pág. 349. 
a) La Recomendación 68/2008 es contundente y clara y está profusamente argumentada. Parte de un problema individual (la queja de la propietaria de una vivienda situada a escasos metros de una autovía, por el ruido padecido) pero eleva una recomendación general al Ministerio de Fomento, para evitar que en el futuro se produzcan situaciones similares. Enfatiza bien la afectación a los derechos al medio ambiente y a la vivienda, citando los artículos 45 y 47 CE (pero sin realizar consideraciones previas sobre el contenido de ninguno de ambos derechos) y hace amplia alusión a la normativa aplicable en materia de carreteras, ruido y otras afines. Quizás la amplitud de referencias resulta excesiva (a veces los árboles no dejan ver el bosque) y hubiera sido preferible citar lo esencial, incluso literalmente, para evitar al lector la búsqueda en las bases de datos de legislación. Extrañamente, la norma aquí clave $^{43}$ no se cita, lo que hubiera sido deseable. Concluye el DP recomendando a la Administración de carreteras, entre otras cosas, que "adopte las medidas de previsión, reducción de la contaminación acústica y cobertura de daños y prejuicios, por ser obligatorio como titular de la carretera de su competencia por mandatos constitucionales y legales". Como se advierte, el DP no se plantea aquí ningún problema interpretativo. Sin embargo, como hemos demostrado en la cita de la Ley 37/2003, algunas dudas interpretativas puede haber, y en todo caso la transformación de una obligación administrativa en contenido de un derecho fundamental exige una argumentación adicional, esto es, una interpretación ${ }^{44}$.

b) La Recomendación 96/2008 hace alusión, muy de pasada, al derecho a la igualdad en el acceso a las funciones públicas, citando al efecto el artículo 23.2 CE, y se muestra clara en su exigencia de aplicación de la norma, en este caso por parte de un Ayuntamiento. En una convocatoria de oposiciones para personal administrativo, el tribunal quedó fijado como sigue: el alcalde (o persona designada por este), un miembro elegido por la Comunidad Autónoma, otro propuesto por la junta de personal y dos funcionarios de carrera, designados por el alcalde. Para el DP, el Ayuntamiento incumplió el Real Decreto 896/1991, que exige que la composición de este tipo de tribunales sea predominantemente técnica y que los vocales posean titulación o especialización iguales o superiores a las exigidas para el acceso a las plazas convocadas. Como en el ejemplo anterior, el incumplimiento de la norma no es

43 A nuestro juicio, se trata del art. 18.2 de la Ley 37/2003, del Ruido, en cuya virtud "Las Administraciones públicas competentes asegurarán que: a) Se adopten todas las medidas adecuadas de prevención de la contaminación acústica [...] b) No se supere ningún valor límite aplicable sin perjuicio de lo dispuesto en materia de servidumbres acústicas". Es importante destacar que el precepto se refiere al futuro otorgamiento de autorizaciones, en nuestro caso para la construcción de una autovía. Para las autorizaciones ya otorgadas (este parece ser el supuesto de la queja presentada al DP) rige más bien el art. 18.3: "El contenido de las autorizaciones [...] podrá revisarse [...] a efectos de adaptarlas a las reducciones de los valores límite.. Nótense las cursivas (evidentemente, nuestras, GE): "asegurarán" (obligación) frente a "podrán" (habilitación).

44 Así, para este tema, G. ESCOBAR ROCA, "Derechos fundamentales y políticas públicas de protección frente al ruido", Nuevas Políticas Públicas, n. 4, 2008, esp. págs. 153-154. 
tan patente y ha mediado actividad interpretativa del DP para llegar a esa conclusión, pues bien puede pensarse que no es preciso que la exigencia de titulación de al menos tres de los cuatro vocales figure expresamente en la convocatoria, pues ya lo dice la norma general. No se dice en la Recomendación que los vocales incumplieran los requisitos del Real Decreto, sino que las bases no reiteraban el Real Decreto, que es algo distinto. Afirmar que el Ayuntamiento incumplió la norma implica deducir de dicha norma el deber de incluir en las bases tales requisitos, algo que la norma expresamente no dice y que por tanto procede de una interpretación de la misma.

c) En la Recomendación 117/2008, sobre la denegación por una entidad financiera privada de admitir un ingreso en horario de caja ${ }^{45}$, se solicita al Secretario de Estado de Economía que "dé cumplimiento a las previsiones legales en materia del régimen de colaboración con las entidades bancarias para los ingresos de los contribuyentes y se tomen las medidas oportunas para el cumplimiento de los convenios de colaboración en el marco de las previsiones del artículo 19.3 del Real Decreto 939/2005". A primera vista, la norma cuya aplicación se exige no admite dudas. Veamos, sin embargo, el tenor literal del precepto: "Las entidades colaboradoras admitirán [...] ingresos todos los días que sean laborables para éstas durante las horas de caja, abonándolos seguidamente en la correspondiente cuenta restringida". Hasta aquí claro; sin embargo, de la cita del precepto el DP llega sin más, sin alusión a ningún otro, a esta conclusión: "El incumplimiento de [la obligación de admitir ingresos] supone la vulneración del reglamento y, por tanto, debe suponer también la apertura del correspondiente procedimiento disciplinario" (cursiva nuestra, GE). Se trata de una deducción evidentemente interpretativa, pues al menos según la mejor doctrina (sin duda discutible ${ }^{46}$ ), la apertura de un procedimiento sancionador es discrecional y por tanto no obligatoria, menos como derecho subjetivo de los ciudadanos.

\section{INTERPRETACIÓN DE UNA NORMA EN UN SENTIDO DIFERENTE AL REALIZADO POR LA ADMINISTRACIÓN}

Se trata del grupo de supuestos más significativo, desde el punto de vista de la determinación del contenido de los derechos. Este grupo de recomendaciones nos parece especialmente relevante, por cuanto demuestra una de las conclusiones más importantes, por originales, de este trabajo, a saber,

45 No se cita ningún derecho fundamental, pudiendo sin embargo pensarse que se están garantizando los derechos implícitos en el art. 51.1 CE.

46 Nótese si no el argumento, poco jurídico, de A. NIETO (en Derecho administrativo sancionador, Tecnos, Madrid, 2. ${ }^{a}$ ed., 1994), que conviene transcribir por su importancia para la labor realizada por el DP: «En mi opinión, el ejercicio de la potestad sancionadora no es obligatorio para la Administración, quien puede, por tanto, iniciar o no los correspondientes expedientes. Sé de sobra que esta tesis repugna el sentimiento de justicia y quebranta el principio de igualdad; pero hay otra razón más pesada que la abona, a saber: la realidad” (cursivas nuestras, GE). 
que el DP no es sólo una Institución de garantía sino también de definición de los derechos.

Veamos tres ejemplos:

a) La Recomendación 1/2008 destaca la diversidad en la solución jurisprudencial otorgada al problema de las diferencias retributivas por razones geográficas. El artículo 8.1 d) del Real Decreto 1909/2000 puede ser interpretado de dos maneras y para el DP la interpretación realizada por la Consejería de Justicia no es correcta, por vulneradora, al parecer (la recomendación no es contundente en este punto), del derecho a la igualdad. En su recomendación, el DP utiliza la seguridad jurídica como argumento complementario. Interesa destacar el uso expreso del principio de interpretación de las normas de conformidad con la CE (art. 5.1 LOPJ): "en la medida en que deben [...] prevenirse interpretaciones opuestas entre sí, que ponen en riesgo el principio de seguridad jurídica, [...] se recomienda [...] una interpretación normativa armonizadora y, por lo tanto, más favorable al derecho de todos los funcionarios destinados en la Fiscalía de las localidades [...] distintas de la capital, a recibir iguales complementos retributivos".

b) En la Recomendación $23 / 2008$ se trata el tema del visado por reagrupación familiar. El DP no lo cita (nuevamente el lector echa de menos las referencias normativas necesarias para entender el asunto), pero conviene recordar que el artículo 17 b) de la Ley Orgánica 4/2000 considera reagrupables a los hijos menores de 18 años. El problema se plantea en cómo acreditar la minoría de edad, una cuestión de hecho pero que afecta a la interpretación del precepto citado. En la práctica, cuando el informe forense señala que el solicitante se encuentra en una franja de edad entre los 17 y los 18 años, la Administración deniega el visado por reagrupación familiar. Para el DP, la interpretación no es correcta, debiendo entenderse, en caso de duda, que el solicitante es menor de edad. En esta ocasión, la argumentación sobre derechos se desvanece, por inconcreta: "se considera más acorde con la salvaguarda de los derechos de las personas la elección del resultado de minoría de edad. Y más adelante, en el cuerpo de la recomendación propiamente dicha, se señala: "que se modifique el criterio de elegir el resultado de mayor edad, al derivarse de él graves perjuicios para los administrados". No es lo mismo, a nuestro juicio, un perjuicio, por grave que sea, que una vulneración (o afectación) de derechos fundamentales.

c) En la Recomendación 32/2008 se plantea una colisión (el DP no se expresa claramente en estos términos) entre la normativa administrativa general (Ley 30/1992) y la especial (Ley Orgánica 2/1986), en cuanto al deber de los funcionarios de identificarse ante los administrados. El DP concluye proponiendo la aplicación de la segunda (la selección de la norma aplicable es una forma de interpretar), recomendando en consecuencia "revisar el procedimiento de notificación de los actos administrativos, en lo que afecta a que en el curso del mismo deban constar los datos personales de los agentes de la Policía Local que llevan a cabo esa función, en aras de la protección del de- 
recho a la intimidad". La invocación del derecho fundamental del artículo 18.1 se hace sin argumentación adicional alguna y sólo por esto resulta ya discutible.

\section{REALIZACIÓN DE UN ACTO ADMINISTRATIVO MATERIAL SIN FUNDAMENTO NORMATIVO CLARO}

Seguramente el número mayor de recomendaciones (al menos en el período analizado) corresponde a esta categoría, de las estudiadas hasta ahora la primera que responde a la singularidad de la tarea de protección de los derechos realizada por el DP. Frente a la respuesta mayoritaria a los problemas de derechos residenciados en los tribunales contencioso-administrativos (obligaciones de abstención, anulando normas o actos), el DP se ocupa preferentemente, en la práctica, de problemas de prestación, revelándose en consecuencia como una Institución clave para la efectividad del Estado social, en el sentido amplio del término. En efecto, son muy frecuentes las recomendaciones que concluyen solicitando a la Administración actuaciones positivas, para la mejor garantía de los derechos fundamentales, correspondan o no estos a la estructura típica de los derechos de prestación en sentido estricto. No es aquí, sin embargo, donde se muestra la singularidad del DP (de momento, sólo hemos hablado de una cuestión estadística, pues es obvio que también los tribunales contencioso-administrativos pueden imponer obligaciones de hacer $\left.{ }^{47}\right)$, sino en la forma de argumentar a favor de la existencia de una obligación administrativa de actuar: normalmente el DP no cita normas jurídicas claras y contundentes sino que se queda en la apelación genérica, en el mejor de los casos, al reconocimiento constitucional de un derecho. Si esto es así, el DP también interpreta, ahora sin decirlo, al menos, la Constitución, pues ninguna duda cabe de que al afirmar que una obligación deriva de un derecho se está interpretando la norma constitucional que lo reconoce. Este modo de argumentar es jurídicamente correcto, aunque dogmáticamente perfectible, como después veremos.

Los ejemplos que proponemos de esta tercera categoría son los siguientes:

a) Las quejas por lentitud en la tramitación de documentos personales son frecuentes en el DP. La Recomendación 4/2008 hace bien en afirmar que la demora en la renovación del DNI, documento necesario para poder viajar a los países que no requieren pasaporte, afecta a la libertad de circulación de los solicitantes: «No se trata de la limitación de la libertad de circulación que trae causa de una prohibición o restricción expresa, sino la que tiene lugar cuando los trámites administrativos que se precisan, por imposición legal, al-

47 En caso de duda, remitimos a la monumental monografía de M. GÓMEZ PUENTE, La inactividad de la Administración, Thomson-Aranzadi, Cizur Menor, 3. a ed., 2002. 
canzan un nivel de complicación o dilación tal que, de facto, los ciudadanos pasan a tomar las decisiones que afectan a sus viajes en función de las dificultades inherentes a poder disponer, o no, de esos documentos". Pues bien, de esta afirmación, sin cita complementaria de disposición legal alguna, se pasa a la recomendación misma: "que se incremente y se adecue la plantilla de personal encargado de la oficina del documento nacional de identidad y pasaporte [...] hasta alcanzar la satisfactoria prestación del servicion. El tipo de razonamiento empleado quizás sorprendería (afortunadamente, añadiríamos nosotros, pues entre otras cosas para complementar la garantía judicial de los derechos se creó el $\mathrm{DP}^{48}$ ) si fuera empleado por un tribunal de justicia.

b) La Recomendación 14/2008 plantea, como la anterior, un problema de medios personales y materiales. Cita diversas normas legales (para defender su inaplicabilidad) pero al final apoya su argumentación en una renovadora (de ahí lo relevante del caso) interpretación del derecho a la igualdad y en la sola cita del artículo 172 del Código Civil, que bien podría haber sido sustituido por el artículo 39 CE. Dice el mencionado artículo 172, por lo que aquí interesa, que "La entidad pública a la que, en el respectivo territorio, esté encomendada la protección de los menores, cuando constate que un menor se encuentra en situación de desamparo [...], deberá adoptar las medidas necesarias para su guarda”. El problema es el siguiente: una Comunidad Autónoma, que tiene saturados los centros de acogida de menores, cuando se encuentra con menores extranjeros no acompañados, inicia como regla el procedimiento para su repatriación. Más que un problema estrictamente jurídico, se trata de una opción por uno u otro sistema de protección de menores. En realidad, el Código Civil aclara poco sobre la opción a seguir y su cita era seguramente innecesaria. Más adecuada es la interpretación que el DP propone del derecho a la igualdad, en términos de derecho a la diferenciación: «El principio de no discriminación no excluye, e incluso puede exigir, la diferenciación entre unos menores y otros, siempre que esa diferenciación encuentre su fundamento en las necesidades especiales (por mayores) de protección". Y más adelante: "en el caso de los menores extranjeros la reunificación familiar, como en el caso de los menores nacionales, puede ser o no la solución idónea, siendo imprescindible llevar a cabo un trabajo individualizado para determinar lo adecuado", para concluir recomendando que "se acuerde declarar el desamparo de los menores extranjeros no acompañados que se encuentren bajo responsabilidad de [la] Administración y que se mantenga éste en tanto no se transfiera la responsabilidad a otra autoridad, se produzca la reagrupación familiar o alcance el interesado la mayoría de edad". Como se advierte, la recomendación diluye en parte lo más interesante de la argumentación anterior, a saber, el deber de la Administración de analizar primero y atender después a las necesidades específicas de cada menor extranjero no acompañado.

48 De interés, G. CARBALLO MARTÍNEZ, La Mediación..., cit., págs. 304-307. 
c) La Recomendación 31/2008 expone un caso curioso, nuevamente revelador de un tipo de asuntos que previsiblemente tendrían mal encaje en la vía judicial. Es sobradamente conocida la disparidad en el cómputo del número de asistentes a las manifestaciones. Los medios de comunicación suelen limitarse a informar de los datos ofrecidos por las instituciones convocantes o por las Administraciones públicas ${ }^{49}$. El DP se centra en esto último, constatando «la percepción de incredulidad que se crea en la ciudadanía si las cifras que ofrecen dos administraciones públicas son tan diferentes que sólo contribuyen a generar desconcierto ciudadano". Seguidamente, el DP alude al artículo $20 \mathrm{CE}$, en términos que conviene transcribir: el precepto citado "reconoce y protege el derecho a comunicar o recibir libremente información veraz por cualquier medio de difusión, siendo en este caso la información a la que se alude la que es facilitada por los poderes públicos a los medios de comunicación para que a su vez éstos se encarguen de difundirla. Difícilmente, pues, se podrá conseguir la formación de una opinión pública libre, como garantía del pluralismo democrático, cuando no se ofrece esta información veraz desde los poderes públicos encargados de su obtención". De esta interpretación, sin duda novedosa, del artículo 20.1 d) $\mathrm{CE}^{50}$, se pasa seguidamente, sin cita de norma legal alguna pertinente al caso, a la recomendación, reveladora de una interesante faceta prestacional de un derecho normalmente configurado como defensivo: "que se arbitren los necesarios mecanismos de coordinación [entre las Administraciones concernidas], creando si procede los pertinentes órganos y comisiones al efecto, al objeto de que, cuando se produzcan grandes concentraciones humanas y manifestaciones [...], se ofrezca información veraz y unificada en cuanto a las cifras de asistentes a las mismas, evitando de esta manera la sensación de desconcierto que se crea en la ciudadanía cuando recibe datos radicalmente diversos como sucede muchas veces en la actualidad".

Si bien se observa, la mayoría de las recomendaciones incluidas en este apartado (en los tres ejemplos expuestos así es), de haberse argumentado de otra manera, habrían encontrado también encaje en las categorías anteriores: aplicación (si se hubiera identificado mejor una norma legal que contuviera obligaciones administrativas más o menos concretas) e interpretación (si se hubiera destacado mejor que se está interpretando, como siempre se hace, la norma de reconocimiento de un derecho fundamental).

49 Para que no todas las referencias sean jurídicas, aconsejamos las referencias al caso contenidas en A. ESPADA, Diarios, Espasa, Madrid, 2002, págs. 140-141, uno de los libros más útiles para entender el funcionamiento de los medios de comunicación.

50 Para la exposición y crítica de la interpretación dominante del art. 20.1 d) CE, G. ESCOBAR ROCA, El estatuto de los periodistas, Tecnos, Madrid, 2002, págs. 47 y ss. 


\section{MODIFICACIÓN DE UNA NORMA}

Con esta y la siguiente categoría llegamos finalmente a las formas de tutela de derechos exclusivas del DP: ningún otro órgano del Estado ejerce con tanta naturalidad y permanencia su competencia expresa para sugerir a los demás órganos una modificación normativa ${ }^{51}$ para la mejor garantía de los derechos fundamentales. Se pone aquí de manifiesto de forma más clara una de las principales virtualidades de la Institución: la garantía objetiva o colectiva de los derechos, yendo así más allá de la función típica de los tribunales, normalmente circunscrita (más por tradición que por naturaleza de la función judicial $^{52}$ ) a la tutela de posiciones jurídicas individuales. En estos casos el DP considera que la mejor solución al problema de afectación de derechos planteado pasa no por la aplicación o interpretación de una norma sino por la modificación normativa o por la creación de una norma nueva. Los supuestos son también numerosos. Por la extensión de su ámbito y como prueba de que el control realizado por el DP incluye, con las matizaciones ya señaladas, al legislador ${ }^{53}$, escogemos dos ejemplos de propuesta de modificación legislativa y otro de modificación reglamentaria a nivel nacional:

a) En la Recomendación 2/2008 se plantea el problema de aquellos ciudadanos (mayoritariamente personas mayores de escasos recursos) que, por la mera posesión de un bien de primera necesidad, han de afrontar el pago de un impuesto que les resulta excesivo, atendiendo a su situación económica. La Recomendación, que cita los artículos 31, 47, 49 y 50 CE, sin apenas argumentar sobre el contenido de los derechos que tales preceptos contienen, concluye recomendando "que se incluya en la Ley Reguladora de las Haciendas Locales una modificación legislativa que establezca una bonificación en el Impuesto sobre bienes inmuebles para sujetos pasivos, cuyo único inmueble en propiedad sea su vivienda habitual y sus rentas no superen determinados ingresos anuales, que fijará el ministerio de acuerdo con su política en materia de protección a las rentas más bajas y procedan, exclusivamente, de pensiones por jubilación o minusvalías o incapacidades".

b) La Recomendación 10/2008 propone la modificación de una norma reglamentaria, en concreto la Orden de Presidencia 1283/2007. Lo relevante del caso (recordemos que no nos interesa tanto el fondo del asunto como

51 Tendríamos también los arts. 20 de la Ley Orgánica 3/1980, del Consejo de Estado, y 109.3 LOPJ, escasamente utilizados, menos en relación con los derechos fundamentales. En cuanto al Tribunal Constitucional, en la práctica ha prevalecido la línea restrictiva abierta por los votos particulares a la STC 53/1985.

52 Discrepamos así de la derrotista concepción de la función judicial expuesta en el por otra parte muy sugerente y recomendable trabajo de R. GARCÍA MANRIQUE, "Los derechos sociales como derechos subjetivos", Derechos y libertades, n. ${ }^{2} 23$, 2010, págs. 93 y ss.

53 Si bien indirectamente, pues al menos las recomendaciones analizadas en este trabajo se dirigen a órganos administrativos, para que promuevan, entendemos, el proyecto de ley correspondiente. 
comprender las formas de razonamiento y las técnicas de protección desarrolladas por el DP) es que la recomendación razona, y muy convincentemente, en torno a la ilegalidad del reglamento. Sin embargo, y esto es lo interesante, no insiste en esa línea $a^{54}$, y no llega por tanto a proponer la anulación sino la modificación de la norma. No está claro el fundamento en derechos (se dice únicamente que la cuestión «está conectada con la intimidad de la persona y su medio familiar, afirmación discutible aunque sólo sea, de nuevo, por su parquedad). El problema es el siguiente: la Orden mencionada obliga, sin fundamento legal, a los extranjeros que pretenden acceder al territorio español por motivos de carácter turístico o privado, a disponer de una carta de invitación de estancia en un domicilio concreto, en la que se acredite el objeto y condiciones de su estancia en España, así como a comparecer personalmente ante el instructor del procedimiento si este lo solicita. La Recomendación acaba proponiendo la supresión del requisito de comparecencia personal y del requisito de justificante del presidente de la comunidad de propietarios especificando el número de personas que conviven en la misma.

c) Otro ejemplo de las recomendaciones realizadas en 2008 de modificación de normas de rango legal es la Recomendación 57/2008, un nuevo y significativo ejemplo de interpretación avanzada del derecho de igualdad, en el sentido de derecho a la diferenciación, en esta ocasión en conexión con el mandato a los poderes públicos de protección de las personas con discapacidad del artículo $49 \mathrm{CE}$. En la práctica, las tarifas aéreas son fijadas libremente por los operadores, sin tener en cuenta las necesidades específicas de este colectivo (p. ej., no suelen fijar tarifas especiales por uso de camilla o asiento especial pero tampoco a favor del acompañante, en muchos casos imprescindible para que la persona con discapacidad pueda desplazarse). En esta ocasión, el DP, que se muestra excepcionalmente contundente en el tono de la recomendación, deja mucha más libertad al legislador que en los ejemplos anteriores, pues ni siquiera se concreta la ley a modificar: "que se estudie la posibilidad de adoptar las medidas necesarias que promuevan las oportunas modificaciones legislativas [...] con el fin de hacer efectivo el derecho a la igualdad de oportunidades de las personas con discapacidad y puedan ejercer su derecho de acceso al transporte aéreo, dado que esta discriminación carece de justificación alguna, por lo que su existencia vulnera ${ }^{55}$ los artículos 9.2 y 49 de la Constitución [...], incluyendo [a las personas con discapacidad] entre los colectivos desfavorecidos y, por tanto, estableciendo bonificaciones".

$54 \mathrm{El}$ ejemplo es nuevamente revelador de la singularidad del modelo de protección ejercido por el DP, basado sobre todo en la ya relatada peculiaridad de su parámetro de control.

$55 \mathrm{El}$ empleo del término "vulnera" es poco habitual en las recomendaciones, normalmente redactadas en términos más matizados y cautelosos. Creemos que sería deseable un mayor empleo del concepto de vulneración, al menos en los casos más graves y evidentes. 


\section{CREACIÓN DE UNA NORMA NUEVA}

La diferencia entre esta categoría y la anterior es coyuntural y escasamente relevante: depende de la estructura previa del ordenamiento en concreto, lo que puede variar. Como ejemplos de esta última categoría proponemos los siguientes:

a) La Recomendación 5/2008 plantea un problema de garantía del derecho a la salud, en concreto relativa al modo de tramitar las reclamaciones administrativas por deficiente asistencia sanitaria a los reclusos. Según la práctica de la Administración penitenciaria, en caso de reclamación, se tiene en cuenta únicamente el informe de los servicios médicos del propio centro penitenciario. Esta realidad es considerada por el DP insuficiente para garantizar, aunque sea a posteriori, el derecho a la salud de los reclusos, y por ello, para solucionar el problema con carácter general, acaba recomendando al Ministro del Interior "que la investigación de las quejas por supuesta actuación irregular con consecuencias graves de los servicios médicos de los centros penitenciarios sea desarrollada por profesionales no pertenecientes a la plantilla del centro en cuestión, instituyéndose al efecto un protocolo normalizado de actuación interna [una norma reglamentaria, en sentido amplio] dentro de los servicios centrales de la Administración penitenciaria".

b) La Recomendación 33/2008 constata la demora en la realización de entrevistas a solicitantes de asilo en una embajada española. Por creer que se trata de un problema general, el DP recomienda al Secretario de Estado de Asuntos Exteriores la creación de una norma reglamentaria en los términos siguientes: "que se elabore un protocolo de actuación para que nuestras representaciones en el exterior tramiten de forma inmediata las peticiones de asilo que reciban, ajustándose rigurosamente a lo establecido en la normativa de asilo".

c) Por último, la Recomendación 63/2008 se refiere a las condiciones de la detención en los municipios. La falta de regulación de los "depósitos" correspondientes implica una merma de las condiciones de los detenidos (la recomendación no cita ningún derecho concreto). Nuevamente, el DP considera que se trata de un problema general y por ello recomienda al Secretario de Estado de Seguridad, en términos muy flexibles y matizados, "que valore la oportunidad de adoptar las iniciativas oportunas para que se proceda a una regulación [no se concreta si legal o reglamentaria] del servicio de depósito [municipal] de detenidos a disposición judicial que, superando las limitaciones de la normativa vigente, establezca un marco jurídico adecuado para la prestación de dicho servicio". 


\section{EL DEFENSOR DEL PUEBLO Y LAS TENDENCIAS ACTUALES DE LA DOGMÁTICA DE LOS DERECHOS.}

Como señalábamos en un comienzo, la atención al contenido material de las recomendaciones del DP permite, entre otras cosas, conectar mejor las definiciones ciudadana y doctrinal de los derechos. Como también indicábamos, un análisis completo de la doctrina del DP excede del propósito de estas páginas. Sin embargo, el estudio de las recomendaciones emitidas en 2008 permite ya adelantar algunas tendencias significativas que enlazan bien con algunos planteamientos dogmáticos renovadores ${ }^{56}$, los cuales, sin ánimo de exhaustividad, pueden concretarse como sigue.

\section{El CATÁlogo de los derechos}

En cuanto al catálogo de los derechos, en las recomendaciones analizadas encontramos la creación, diríamos que pretoriana, de nuevos derechos, esto es, no contenidos expresamente en el listado de la CE. Como es sabido, nuestro catálogo es esencialmente cerrado (con las dos cláusulas relativas ${ }^{57}$ de apertura del art. 10, la dignidad de la persona y el Derecho internacional) y por algún lado tenía que abrirse, si se quiere mantener la deseable estabilidad del texto, tarea en la que el constitucionalismo estadounidense, como en tantas otras cosas, es maestro. Ciertamente, el DP no afirma de modo expreso que esos nuevos derechos sean fundamentales, ni siquiera que sean derechos, pero también es cierto lo siguiente: el DP, en principio, sólo protege derechos fundamentales (art. $54 \mathrm{CE}$ ) y el acceso natural al DP es mediante la queja de los interesados, luego si el DP está respondiendo (además, con resolución estimatoria) a tal queja, está creando derechos subjetivos ${ }^{58}$. Estos nuevos derechos (o si se quiere, según los casos, estas nuevas y ampliadas determinaciones del contenido de derechos ya previstos en el catálogo) bien podrían servir de inspiración a la dogmática, para que esta, con mayor argumentación, expandiera en el futuro el listado de los derechos fundamentales ${ }^{59}$. No se ol-

56 Para un sintético panorama de casi todos ellos, G. ESCOBAR ROCA, Introducción..., passim. En la doctrina posterior recomendamos la lectura del trabajo de W. KAHL, "Neuere Entwicklungslinien der Grundrechtsdogmatik. Von Modifikationen und Erosionen des grundrechtlichen Freiheitsparadigmas", Archiv des öffentlichen Rechts, n. ${ }^{\circ} 131,2006$, págs. 579 y ss.

57 Relativas, porque en rigor no son cláusulas de apertura del catálogo propiamente dicho sino más bien del contenido de los derechos ya reconocidos en el mismo catálogo. De interés, M. J. CORCHETE MARTíN, "Los nuevos derechos", Teoría y Realidad Constitucional, n. ${ }^{\circ}$ 20, 2007, esp. págs. 547 y ss.

58 Salvo que se quiera defender que los derechos subjetivos exigen, por definición, la tutela judicial, tesis ésta sobre la cual no existe unanimidad en la doctrina.

59 Obviamente con cautelas, pero quizás no con tantas como las señaladas por S. SÁNCHEZ GONZÁLEZ, "¿Todavía más derechos? ¿De qué derechos hablamos?”, Teoria y Realidad Constitucional, n. ${ }^{\circ}$ 25, 2010, págs. 297 y ss., donde casi se propone un retroceso histórico. 
vide que esos nuevos derechos no son pura invención del DP, que raramente actúa de oficio, sino que responden a las inquietudes de los ciudadanos.

Entre los nuevos derechos que van consolidándose en la doctrina del DP destacaríamos los derechos al procedimiento administrativo en sentido amplio (sólo tangencial y fragmentariamente reconocidos en la CE y tampoco reconocidos en su plenitud en la propia Ley 30/199260), del más variado signo, resultando de especial significación, por la reiteración con la que aparece, un singular y novedoso derecho a la documentación ${ }^{61}$. Con carácter más general, podría hablarse de un derecho al cumplimiento de la legalidad ${ }^{62}$, de un derecho a la seguridad jurídica ${ }^{63}$ e incluso de un derecho a la coordinación y a la eficacia administrativa ${ }^{64}$, facultades que podrían emparentarse, de un modo $\mathrm{u}$ otro, con un novedoso derecho fundamental a la buena administración ${ }^{65}$. Por otro lado, más como mecanismo de ampliación del contenido de los derechos del catálogo que de creación de derechos nuevos, la práctica del DP pone de manifiesto la posibilidad de subjetivizar las obligaciones administrativas conectadas con derechos fundamentales ${ }^{66}$, una tendencia general, por cierto, del Derecho público de nuestro tiempo, destacada ya hace algunos años por nuestra mejor doctrina ${ }^{67}$.

60 Últimamente, p. ej., M. SÁNCHEZ MORÓN, "Reflexiones sobre la participación del ciudadano en las funciones administrativas en el sistema constitucional español", Revista catalana de Derecho público, n. ${ }^{\circ} 37,2008$, esp. págs. 232-234, donde contundentemente se afirma: «la práctica de las fórmulas de participación individual [...] es una práctica deficiente en nuestro país". Para paliar este déficit, la doctrina del DP ofrece un panorama más abierto y garantista; vid., p. ej., sin conexión directa con derechos fundamentales (tampoco con el art. 25.1 CE), las Recomendaciones 13, 23, 25, 42, 59, 61, 64, 66, 74, 79 o 115/ 2008.

61 P. ej., Recomendaciones 80, 104, 113, 114 o 120/2008.

62 Excepcionalmente como derecho autónomo: p. ej., Recomendación 98/2008.

63 P. ej., Recomendaciones 9, 24 o 107/2008.

64 P. ej., Recomendaciones 36, 54, 101, 103, 107 o 121/2008.

65 Reconocido como tal en el art. $41 \mathrm{CDF}$, vinculante ahora para el intérprete por la vía del art. 10.2 CE, y en alguno de los nuevos Estatutos de Autonomía. En su análisis del tema, G. CARBALLO MARTíNEZ (La Mediación..., cit., págs. 231 y ss.) no acaba de concretar el contenido de un derecho fundamental autónomo, un reto importante y pendiente que no podemos afrontar ahora. A nuestro juicio, el tratamiento de este tema debería caminar de la mano de la dogmática de los derechos fundamentales, no tanto de la ética administrativa ni de los principios del Derecho administrativo, aunque ambas perspectivas pudieran servir de inspiración.

66 Sirvan como ejemplo las recomendaciones expuestas en el apartado III.3 de este trabajo, a las que podrían añadirse muchas más.

67 L. PAREJO ALFONSO, Crisis y renovación en el Derecho público, CEC, Madrid, 1991, esp. págs. 70-71. En materia de derechos fundamentales, últimamente, con amplia atención a la doctrina alemana, G. DOMÉNECH PASCUAL, Derechos fundamentales y riesgos tecnológicos, CEPC, Madrid, 2006, esp. págs. 69 y ss. y J. C. GAVARA DE CARA, "La vinculación positiva de los poderes públicos a los derechos fundamentales", Teoría y Realidad Constitucional, n. ${ }^{\circ} 20,2007$, esp. págs. 312 y ss., trabajos estos dos últimos sin duda importantes y recomendables pero no siempre claros en su respuesta al problema capital de la subjetivación de las obligaciones estatales de protección. 


\section{La estructura DE LOS DEREChos}

El modelo argumentativo clásico de análisis de las intervenciones sobre los derechos fundamentales estaba pensado para los derechos de defensa ${ }^{68}$. Como se ha señalado, la mayoría de las actuaciones del DP concluyen recomendando a la Administración obligaciones de hacer, tanto en materia de típicos derechos de defensa (en este trabajo hemos visto ejemplos sobre libertad personal, intimidad, libertad de circulación, información veraz o acceso a la función pública) como en materia de típicos derechos de prestación. Entender las intervenciones o afectaciones a los derechos en un sentido amplio (no sólo como actuaciones positivas sino también como omisiones y, más frecuentemente, como actuaciones insuficientes) puede ayudar a nuestra dogmática a revisar el planteamiento tradicional y a perfeccionar los incipientes análisis desarrollados en materia de derechos de prestación o, lo que viene a ser lo mismo desde el punto de vista estructural, de la faceta prestacional de los derechos de defensa ${ }^{69}$.

De otro lado, la doctrina del DP sobre las obligaciones positivas relacionadas con derechos fundamentales confirma la tendencia reciente, que ya podemos considerar mayoritaria, que minimiza las diferencias estructurales entre los derechos de defensa y los derechos de prestación ${ }^{70}$.

\section{Los titulares De los DeRechos}

Otra tendencia manifestada en las actuaciones del DP, en línea con el Derecho internacional ${ }^{71}$ (que no suele distinguir en la titularidad de derechos en-

68 Una vez más, la dogmática alemana es pionera en la crítica a este reduccionismo, al menos desde el clásico trabajo de D. GRIMM, "¿Retorno a la comprensión liberal de los derechos fundamentales", ahora en Constitucionalismo y derechos fundamentales, Trotta, Madrid, 2006, págs. 155 y ss. En castellano, puede verse el también clásico de R. ALEXY, Teoría de los derechos fundamentales, CEC, Madrid, 1993, donde los derechos de prestación (en sentido amplio) se integran ya con toda naturalidad.

69 Nos referimos a la doctrina española, pues la alemana está oportunamente desarrollada (casi diríamos que demasiado, por la extrema complejidad de sus construcciones) en este punto. Entre nosotros, de momento, pese a lo discutible de sus tesis, G. DOMÉNECH PASCUAL, Derechos fundamentales..., cit., esp. págs. 143-181.

70 El influyente (quizás más en América Latina que en España) y sin duda importante trabajo de V. ABRAMOVICH y C. COURTIS, Los derechos sociales como derechos exigibles, Trotta, Madrid, 2002, esp. págs. 21-37, ha sido seguido por la práctica totalidad de la doctrina española posterior sobre derechos sociales. Para una selección reciente de referencias, R. GARCÍA MANRIQUE, "Los derechos sociales...", cit., págs. 74-75.

71 La simpatía por el Derecho internacional (Völkerrechtsfreundlichkeit) se sitúa sin duda entre las más importantes tendencias de la dogmática actual de los derechos fundamentales; por todos, W. KAHL, "Neuere Entwicklungslinien...", cit., pp. 582-585. Las recientes tendencias del Derecho de la Unión son también significativas: G. ESCOBAR ROCA, "Elementos de teoría de los derechos fundamentales de la Unión Europea", Revista catalana de Derecho público, n. 37, 2008, págs. 383-384. 
tre nacionales y extranjeros, al menos con la contundencia característica de textos constitucionales como el español) y especialmente con la jurisprudencia del Tribunal Europeo de Derechos Humanos ${ }^{72}$, resulta ser la afirmación de la universalidad de los derechos ${ }^{73}$ : un buen número de los casos atendidos por el DP se dedica esencialmente a afirmar la necesidad de un igual reconocimiento de derechos entre españoles y extranjeros ${ }^{74}$.

En otro orden de consideraciones, todavía más relevante, cabe citar la nueva concepción de la igualdad que se desprende de la doctrina del DP, en el sentido de configurar un auténtico derecho (aunque, como es habitual, se evitan consideraciones expresas y generales al respecto) al trato diferenciado, todavía por consolidar en nuestra dogmática ${ }^{75}$. El planteamiento queda patente sobre todo en los asuntos relacionados con los colectivos (que podríamos llamar desfavorecidos) expresamente citados en la CE. Si bien se mira, en ninguno de estos casos la $\mathrm{CE}$ reconoce en propiedad derechos fundamentales, y sin embargo, el DP en la práctica termina haciéndolo, utilizando complementariamente (en ocasiones) el artículo 9.2 (y a veces también el 14, lo que resulta más novedoso), para recomendar a la Administración e incluso al legislador actuaciones tendentes a mejorar la situación de estos colectivos. Ya hemos hecho referencia a los extranjeros (desde este nuevo punto de vista, más bien inmigrantes), a la Recomendación 2/2008, sobre la tercera edad, y a la Recomendación 57/2008, sobre las personas con discapacidad, pero hay muchas otras relevantes, sobre esta última materia ${ }^{76} \mathrm{y}$, en parecido sentido, sobre menores ${ }^{77}$, a las que podrían añadirse las relativas a los reclusos ${ }^{78}$, colectivo este, como es sabido, con especiales problemas de protección de derechos.

72 Uno de las aportaciones más llamativas del TEDH, en contraste con la jurisprudencia de los Tribunales Constitucionales nacionales, es precisamente la extensión de la titularidad de la práctica totalidad de los derechos a los extranjeros.

73 Entendemos aquí universalidad en un sentido algo diferente al utilizado en el Derecho internacional y en la Filosofía del Derecho. Pensamos más bien en titularidad universal de los derechos fundamentales dentro del ámbito de aplicación de una Constitución nacional.

74 P. ej., Recomendaciones 10, 11, 12, 14, 16, 23, 50, 71, 72, 74, 77, 78, 80, 89, 118 o $120 / 2008$.

$75 \mathrm{Al}$ menos, esta es la opinión (crítica) de E. COBREROS MENDAZONA, "Discriminación por indiferenciación: estudio y propuesta", Revista española de Derecho constitucional, n. ${ }^{\circ} 81,2007$, págs. 72 y ss.

76 P. ej., Recomendaciones 57, 59, 92, 93 o 97/2008. Para una perspectiva más amplia de esta doctrina, FEDERACIÓN IBEROAMERICANA DE OMBUDSMAN, VII Informe sobre Derechos Humanos: Personas con discapacidad, Trama, Madrid, 2010, págs. 571 y ss.

77 P. ej., Recomendaciones 14, 23, 74, 77, 80, 89, 90, 91 o 112/2008. Para una perspectiva más amplia de esta doctrina, FEDERACIÓN IBEROAMERICANA DE OMBUDSMAN, III Informe sobre Derechos Humanos: Niñez y adolescencia, Trama, Madrid, 2005, págs. 431 y ss.

78 P. ej., Recomendaciones 5, 6, 20, 47, 49, 76, 102 o 114/2008. Para una perspectiva más amplia de esta doctrina, FEDERACIÓN IBEROAMERICANA DE OMBUDSMAN, V Informe sobre Derechos Humanos: Sistema penitenciario, Trama, Madrid, 2007, págs. 458 y ss. 


\section{LOS OBLIGAdOS POR LOS DERECHOS}

Sobre este punto, además de reiterar lo señalado sobre la mayor vinculación de la Administración que se deriva de la subjetivación de las obligaciones administrativas relacionadas con derechos fundamentales, debe destacarse la entrada natural de la Drittwirkung en la doctrina del DP, lo que resulta especialmente significativo, teniendo en cuenta que, en principio y como ya sabemos, legalmente los particulares no figuran entre los sujetos controlados por la Institución. El argumento, reiteradamente ensayado por la dogmática desde hace años, consiste, como es conocido, en entender que existe un deber genérico del Estado de proteger a los ciudadanos frente a las vulneraciones de sus derechos ocasionadas por otros particulares; cuando estas vulneraciones se producen, el Estado es responsable por omisión ${ }^{79}$, pudiendo citarse al respecto las Recomendaciones 13/2008 (sobre centros docentes concertados), 38/2008 (sobre actuaciones urbanísticas ilegales), 39/2008 (sobre la venta de armas) o las ya citadas 57/2008 (sobre tarifas aéreas) y 117/2008 (sobre entidades de crédito).

\section{LAS GARANTías De LOS DERECHOS}

El DP acentúa especialmente una garantía importante de los derechos fundamentales, que tiene la virtualidad de evitar el casi siempre lento y costoso recurso a los tribunales: la que tiene lugar en el seno de la Administración. Téngase en cuenta que no nos referimos a derechos fundamentales de procedimiento típicamente administrativos (aun desde la generosa concepción, ya aludida, del DP) sino a garantías procedimentales de derechos sustantivos, aunque en muchas ocasiones (una vez más) el DP no cite expresamente tales derechos sustantivos. En esta dirección cabe recordar las ya citadas Recomendaciones 5/2008, sobre la garantía del derecho a la salud de los reclusos o $33 / 2008$, sobre el derecho de asilo, pudiéndose añadir muchas otras, como las 23 y 78/2008 (sobre reagrupación familiar), 27/2008 (sobre integridad física), $35,62,65,83,84$ y 94/2008 (sobre legalidad de las sanciones administrativas), $41 / 2008$ (sobre seguridad social) o 61 y 66/2008 (sobre propiedad privada), en las cuales se pone de manifiesto la importancia de la existencia y efectivo funcionamiento de las reglas clásicas, convenientemente subjetivadas y ampliadas, del procedimiento administrativo, como la información, la imparcialidad, la presunción de inocencia, la prueba o la proporcionalidad, entre otras, para una protección más efectiva de los derechos fundamentales ${ }^{80}$.

$79 \mathrm{El}$ argumento es meramente procesal y no se pronuncia sobre la tesis mediata o inmediata de la Drittwirkung. Como es sabido, nuestro Tribunal Constitucional lo utiliza desde antiguo, interpretando el art. 44 LOTC de forma bien distinta a la derivada del tenor literal del precepto.

80 La garantía administrativa de los derechos fundamentales, bien conocida en la doctrina alemana, es otra de las lagunas de la nuestra, como tantas veces sucede, por encontrarse a caballo de dos disciplinas que pocas veces dialogan, el Derecho constitucional y el Derecho administrativo. 


\section{VALORACIÓN Y PROPUESTA}

A lo largo de este trabajo hemos expuesto diversos ejemplos, sistemáticamente ordenados, de recomendaciones del DP orientadas a la garantía de los derechos, y simultánea y fragmentariamente, hemos llamado la atención sobre algunas carencias argumentativas de tales recomendaciones. Los aspectos positivos son sin duda los dominantes (si el DP no existiera, habría que crearlo, y siempre serán útiles los esfuerzos del Parlamento y de la Administración en incrementar sus medios personales y materiales, y sobre todo, en hacer un uso más frecuente de los documentos emanados de la Institución), y creemos que han sido destacados de manera suficiente en los apartados anteriores. En este punto y para concluir de forma breve, conviene destacar únicamente los aspectos negativos (que son los menos), con la intención de esbozar algunas propuestas constructivas de futuro, que en nuestra modesta opinión, coadyuvarían a mejorar la tarea de garantía de los derechos fundamentales desarrollada por el DP.

En síntesis, los señalados aspectos negativos se reducen a un relativo déficit de argumentación, y esto resulta aquí de gran trascendencia: como es sabido, el DP apoya la eficacia de su labor (léase, el mayor cumplimiento de sus recomendaciones) no en la típica coacción jurídica, de la que la Institución carece, sino en la fuerza persuasiva de su razonamiento ${ }^{81}$, y sin duda, precisar mejor las normas aplicables ${ }^{82}$, explicitar de manera más completa sus opciones interpretativas y, sobre todo, argumentar más y mejor a partir de derechos fundamentales bien definidos ${ }^{83}$, redundaría a favor de la autoridad de la Institución y por ende de la efectividad final de tales derechos. Como hemos pretendido demostrar, el DP interpreta siempre los derechos fundamentales antes de invocarlos, pero esta interpretación, que es muchas veces creativa y siempre interesante para el estudioso, normalmente no se explicita ${ }^{84}$. Los derechos fundamentales no son sólo normas, son también ideales políticos ${ }^{85}$ y argu-

81 Sobre el tema, de interés, G. CARBALLO MARTíNEZ, La Mediación..., cit., págs. 253 y ss. Asimismo, G. ESCOBAR ROCA, "Del Derecho débil a la fuerza de los derechos", en El Ombudsman en el sistema internacional de derechos humanos: contribuciones al debate, Dykinson, Madrid, 2008, págs. 17 y ss.

82 Si el razonamiento puede fundarse en la ley, mejor aprovechar la oportunidad y no diluir la argumentación en consideraciones morales, y ello no sólo porque se persuadirá mejor a la Administración sino también por razones democráticas (democráticamente, vale más el argumento de la ley que el de la mera autoridad moral del DP).

83 Como hemos venido observando en varios ejemplos (y podrían citarse muchos más), el DP en ocasiones o no cita derecho fundamental alguno, pudiendo hacerlo, o lo cita pero sin extenderse apenas sobre los motivos que le llevan a dotarle de un determinado contenido.

84 Casi podríamos hablar de un exceso de timidez (o de mal entendida deferencia hacia los poderes públicos) del DP, que a veces recurre al argumento de autoridad (de la jurisprudencia o del Derecho internacional), casi siempre como único argumento, como si no se atreviera a sentar una doctrina propia. ss.

85 Nuevamente, por todos, R. GARCÍA MANRIQUE, “Los derechos sociales...”, cit., págs. 85 y 
mentos persuasivos, y para utilizarlos mejor sería deseable manejar (y hacerlo presente) una buena dogmática ${ }^{86}$. Parafraseando al viejo KANT, no puede existir una buena práctica sin una buena teoría que la sirva de fundamento, la preste orientación y la dote de coherencia y estabilidad.

TITLE: Interpretation and protection of fundamental rights by the Ombudsman.

ABSTRACT: The study of the doctrine of the Ombudsman is important because it provides a more comprehensive and adequate to the social reality of constitutional law in general and fundamental rights in particular. This paper describes the model of fundamental rights' protection developed by the Ombudsman, whose characteristics emphasizes the originality of the control parameter. Then proposes a systematization of its formal recommendations in four categories and summarizes the essential content of their recommendations, in dialogue with modern trends of the Theory of rights. It concludes with a proposal for the future to improve the performance of the task undertaken by the Ombudsman, based on increased support of its modes of argument in the Theory of rights.

ReSUMEN: El estudio de la doctrina del Defensor del Pueblo es importante porque aporta una visión más amplia y adecuada a la realidad social del Derecho constitucional en general y de los derechos fundamentales en particular. Este trabajo describe el modelo de garantía de los derechos fundamentales desarrollado por el Defensor del Pueblo, entre cuyas características destaca la originalidad del parámetro de control utilizado. Seguidamente, propone una sistematización de sus recomendaciones en cuatro categorias formales y resume las lineas esenciales del contenido de las mismas, en diálogo con las más modernas tendencias de la dogmática de los derechos. Se concluye con una propuesta de futuro para el mejor desempeño de la tarea desempeñada por el Defensor del Pueblo, basada en un mayor apoyo de sus modos de argumentación en la dogmática de los derechos.

Key Words: Ombudsman. Fundamental rights. Human Rights. Rule of Law and Political Accountability.

Palabras Clave: Defensor del Pueblo. Derechos fundamentales. Derechos humanos. Estado de Derecho y control de los poderes públicos.

FECHA DE RECEPCIÓN: 02.07.2010. FECHA DE ACEPTACIÓN: 28.07.2010.

86 Que para persuadir hay que argumentar bien y que para ello hay que tener una buena teoría ya fue puesto de manifiesto hace tiempo por GADAMER y, en menor medida, por PERELMAN. Para una panorámica reciente, M. ATIENZA, El Derecho como argumentación, Ariel, Barcelona, 2006, esp. págs. 279 y ss. 